\title{
Comunicación del Comité Científico
}

Estimados colegas:

A nombre del Comité Científico organizador de este Congreso quisiera agradecer a todos y a cada uno de ustedes la colaboración brindada para que pudiéramos salir adelante en esta misión. No ha sido fácil ni cómoda; pero sí muy gratificante y esperamos que el resultado de muchas horas de esfuerzo sea plasmado en una reunión de gran importancia para nuestra sociedad y sus miembros.

Este Congreso se gestó hace tres años, fecha en la cual se tomó el compromiso de realizarlo en conjunto con la Sociedad Hispano Alemana de Otorrinolaringología, la cual por primera vez en su historia y en forma extraordinaria realiza un Congreso fuera de Europa. Es un gesto que aceptamos teniendo como meta organizar un evento de igual o mejor nivel que los que hemos visto en España y Alemania La colaboración y participación de nuestros colegas españoles y alemanes ha sido masiva y es así como tendremos a numerosos de ellos participando en cursos, mesas redondas, conferencias, temas libres y pósters.

Con la idea que estas reuniones puedan realizarse en otros lugares de Latinoamérica se han invitado a colegas de Perú, Argentina, Brasil, Panamá y Venezuela, los que participarán en todas las actividades anteriormente descritas.

Los socios de la Sociedad Chilena de Oorrinolaringología, Medicina y Girugía de Cabeza y Quello han sido también masivamente invitados a participar. La colaboración con la máxima reunión científica de nuestra organización se ve reflejada en la participación de un tercio de todos nuestros socios.

Las reuniones científicas se harán simultáneamente en los salones Lonquimay, Araucanía y Llaima. Los dos primeros contarán durante todo el evento con traducción simultánea españolalemán y alemán-español. La presentación de los temas libres se hará en un horario privilegiado y cada expositor tendrá 5 minutos para presentar su tema y luego de dos presentaciones habrá 5 minutos para discutir los dos temas presentados. Los cursos y mesas redondas serán de una hora de duración. Las conferencias serán de 15 minutos y sólo tendrán posibilidad de discusión si el expositor no ocupa todo su tiempo. Las controversias durarán también 15 minutos y cada expositor tendrá 5 minutos para plantear su posición y luego el moderador dispondrá de 5 minutos para discusión.

Como comprenderán la agenda de todas las actividades es muy acotada de modo que el cumplimiento del horario será de extrema necesidad y cautelado en forma estricta por el Comité Audiovisual el que avisará oportunamente a cada expositor si su tiempo ha terminado.

La idea que nos llevó a tener esta agenda tan apretada se debe a que la cantidad de tiempo para programa científico es corta, queremos que el máximo número de colegas nacionales participe, por otro lado tenemos además de los chilenos, un gran número de exponentes extranjeros de excelente calidad. $日$ tiempo asignado a cada presentación puede parecer corto; pero en ese tiempo se alcanza a decir lo más importante, y si quedan dudas, se han planificado largas horas de almuerzo que estimulan a los colegas a mantener contacto y resolver esas dudas.

Por último quiero agradecer a todo el Comité Científico su ayuda y sus consejos durante la organización y el desarrollo de este evento. 